\title{
A Process Model for Enhancing Digital Assistance in Knowledge-Based Maintenance
}

\author{
Klaudia Kovacs ${ }^{1,2^{*}}$, Fazel Ansari ${ }^{1,2}$, Claudio Geisert ${ }^{3}$, Eckart Uhlmann ${ }^{3,4}$, \\ Robert Glawar ${ }^{2}$, Wilfried Sihn ${ }^{1,2}$ \\ ${ }^{1}$ Vienna University of Technology (TU Wien), Institute of Management Science \\ ${ }^{2}$ Fraunhofer Austria, Division of Production \& Logistics Management, Vienna, Austria \\ ${ }^{3}$ Fraunhofer Institute for Productions Systems and Design Technology IPK, Berlin, Germany \\ ${ }^{4}$ Institute for Machine Tools and Factory Management, TU Berlin, Berlin, Germany \\ klaudia.kovacs@tuwien.ac.at
}

\begin{abstract}
Digital transformation and evolution of integrated computational and visualisation technologies lead to new opportunities for reinforcing knowledge-based maintenance through collection, processing and provision of actionable information and recommendations for maintenance operators. Providing actionable information regarding both corrective and preventive maintenance activities at the right time may lead to reduce human failure and improve overall efficiency within maintenance processes. Selecting appropriate digital assistance systems (DAS), however, highly depends on hardware and IT infrastructure, software and interfaces as well as information provision methods such as visualization. The selection procedures can be challenging due to the wide range of services and products available on the market. In particular, underlying machine learning algorithms deployed by each product could provide certain level of intelligence and ultimately could transform diagnostic maintenance capabilities into predictive and prescriptive maintenance. This paper proposes a process-based model to facilitate the selection of suitable DAS for supporting maintenance operations in manufacturing industries. This solution is employed for a structured requirement elicitation from various application domains and ultimately mapping the requirements to existing digital assistance solutions. Using the proposed approach, a (combination of) digital assistance system is selected and linked to maintenance activities. For this purpose, we gain benefit from an in-house process modeling tool utilized for identifying and relating sequence of maintenance activities. Finally, we collect feedback through employing the selected digital assistance system to improve the quality of recommendations and to identify the strengths and weaknesses of each system in association to practical usecases from TU Wien Pilot-Factory Industry 4.0.
\end{abstract}

Keywords: Maintenance, Digital Assistance Systems, Process Model, Industry 4.0.

\section{Introduction}

\subsection{Digital Assistance in Knowledge-Based Maintenance}

Maintenance is a knowledge-intensive process in which the process participants (organizations or (group of) individuals involved in the maintenance process and sub-process(es) either as internal or external stakeholders) create, (re)use, and share specialized professional knowledge, while enriching their implicit and experiential knowledge. Considering maintenance organization as a learnable unit, it encompasses the creation, 
acquisition, extraction, storage, retrieval, discovery, application, review, sharing and transfer of the knowledge captured from/within maintenance processes. To this end, Knowledge-Based Maintenance (KBM) continuously supports value generation and facilitates developing and protecting maintenance collective knowledge across maintenance organization, which is enhanced by a variety of data-driven, digital technologies and artificial intelligence (AI) techniques, including advanced statistics, stochastics, real-time computing and analytics, machine learning algorithms, static rule-based or dynamic model-based analytics, and sematic modelling and representations [1],[2]. From a practical point of view, maintenance operators and engineers are frequently associated with a wide range of difficulties due to the increasing complexity of manufacturing systems, in terms of products, processes and systems, namely: i) a wide range of maintenance tasks from diagnosis to repair, ii) increasing complexity of maintenance requirements and iii) a large number of equipment types to maintain [3],[4]. Additionally, they are constantly confronted with situations in which the experiential knowledge of other employees is needed, particularly in the confrontation with new or rarely occurring tasks and circumstances. The challenge that arises with increasing complexity is a shortage of skilled workers and the time required to build up relevant experience [5].

With the digitization of the industry and the recent technological advancements of computing and visualization technologies, the opportunity to access actionable information for maintenance operators and engineers provides additional benefits. The increasing integration of ICT technologies in classical automation as well as a constantly increasing digital database enable them to capture information through a real time interaction [6], [7]. According to our experiential knowledge, almost $90 \%$ of maintenance practitioners use a notebook as a tool to obtain information for their maintenance tasks. Nevertheless, hardcopies build the second most common information source. The study participants consider the active support of the diagnosis as well as the availability of information and checklists for the respective process steps to be the most helpful measures during the service visit [8]. Digital assistance systems (DAS) can enhance human performances, depending the degree of digitization, by providing relevant information for a given specific task [9]. Maintenance operators and engineers can capture information through the used device more quickly and more precisely, while they are performing maintenance, inspection or repair tasks [10]. Recent studies show that DAS can increase maintenance practitioners' productivity by $8.5 \%$ [3]. However, the reason for selecting a device rather than another is not always trivial and relates to context of application, environmental conditions, the user and the process related requirements [11]. In order to select and make decision on an appropriate device to assist maintenance operators, organisations need to take multiple decision criteria and preferences into account [13]. Research surveys show that companies confront major challenges in implementing digital assistance solutions due to high investment costs and technological issues such as: i) choosing the right hardware, ii) development of a software and realizing a suitable visualisation method and iii) supplying adequate information to improve human performances by providing relevant information regarding both corrective and preventive maintenance [11], [12], [14]. The selection procedures can be challenging due to the wide choice of services (options) available on the market. 
Considering the discussion above, this paper presents an approach to improve the maintenance efficiency through DAS using a morphological approach for the proper hardware selection combined with a process-modeling tool providing the adequate information to fulfill the needed maintenance task. The goal of the proposed process model is to systematically identify functionalities of the emerging technologies on the market and apply the functionalities to requirements in order to find appropriate assistance systems for various industrial applications. Therefore, an overview on present digital assistance solutions is given and a morphological approach for the elicitation of derived requirements on digital assistance solutions is presented.

\subsection{Digital Assisted Maintenance (DAM)}

The emergence of novel wearable technologies (in this paper referred to as a type of DAS) such as smart glasses, smart watches and tablets spurred new concepts of service support systems [9]. DAS combined with Cloud manufacturing concepts provide an opportunity to deal with the increasingly complex maintenance procedures [3], [9]. DAS create the potential to shape new working environments in which modern technology is used to assist workers in activities that are challenging in terms of their cognitive complexity [14]. Via interfaces, corresponding process data are processed and visualized by software components embedded into assistance system to support maintenance operators with relevant information, e.g. by means of head-mounted displays or portable devices. A strong focus of literature is the exploration and identification of application areas for implementing and deploying DAS [5]. To implement DAS, the service-oriented architecture approach has become established. Although innovative technologies, e.g. web services, have already been employed in industrial applications [15], [16], their usage in maintenance support has not been sufficiently well emphasized. A preliminary chronological market and literature analysis with regard to suitability and industrial applicability (i.e. technology readiness) of DAS, in particular wearable devices, is shown in Fig.1.

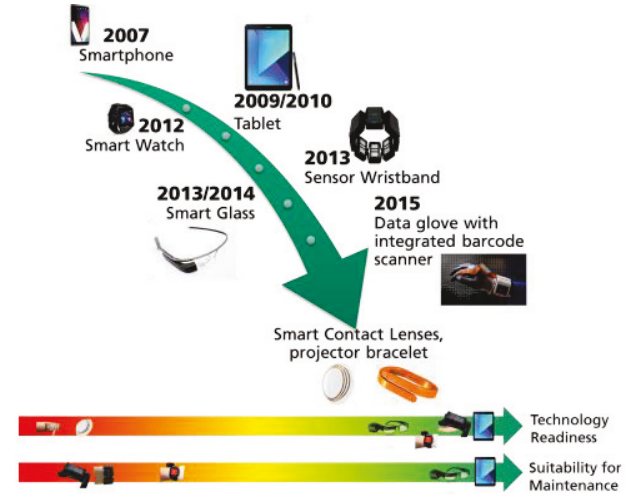

Fig. 1. Overview of digital assistance systems on the market and their market entrance.

As a result, the four most common DAS in industrial application are: industrial tablets, smart watches, smart phones and head mounted displays [12], [17], [18], [19]. While the pros and cons of handheld devices (industrial tablets, smart watches, smart 
phones) are well known and elaborated in literature, the potential of head-mounted displays are disputed. The most value-creating functionalities of head mounted displays lie in information provision, environmental identification and tracking [6]. The opportunity to access information hands free provides additional benefits. However, due to various technical limitations and challenges, such as wear comfort or poor wireless network connections, the question of usefulness in maintenance still arises.

\section{Selection Methodology}

This section explains the methodology of the developed model to select proper DAS for maintenance tasks. The proposed model builds on three integrated elements (see Fig. 2): i) Morphological Approach, ii) Application Layer and iii) Device Selection Layer.

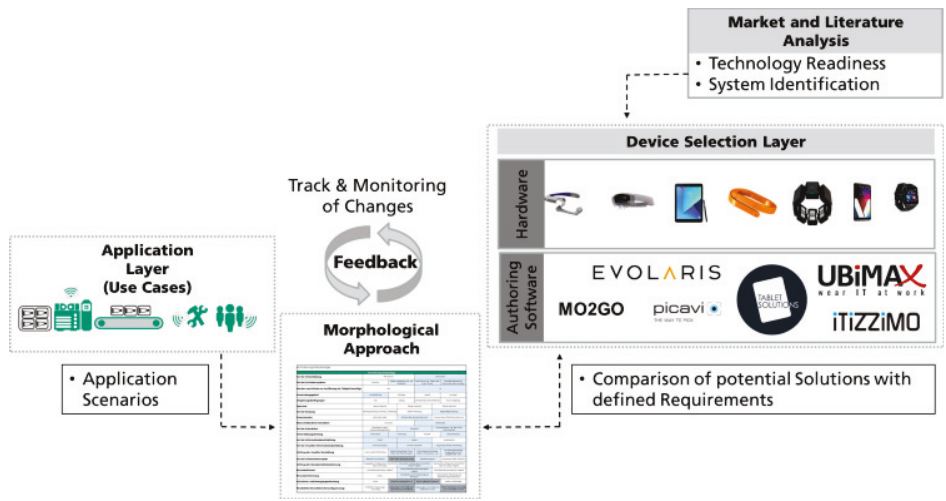

Fig. 2 3-layer model for selecting proper digital assistance systems

The first element represents a morphological box, which has been developed to facilitate and optimize the selection of suitable DAS. The second element represents the application domain. The application layer provides the individual user-specific system requirements as well as application scenarios (i.e. describing and representing maintenance activities). Subsequently, the system and hardware requirements resulting from i) the predefined parameters of the requirement morphology and ii) from the application level are evaluated and, according to their overall systemic meaning, compared with the potential technology solutions. Algorithms and correlation-analyses within this system are used to ultimately map the requirements to existing digital assistance solutions. Using the proposed approach, a (combination of) DAS is selected and linked to maintenance activities. Finally, we collect feedback through employing the selected digital assistance system to improve the quality of recommendations and to identify the strengths and weaknesses of each system in association to practical use-cases.

\subsection{Morphological approach}

In order to facilitate and optimize the selection of suitable DAS for supporting maintenance operations in manufacturing industry, a morphological approach has been developed. A Morphological Analysis (MA) represents a method for systematically structuring and analyzing a set of relationships contained in multi-dimensional, nonquantifiable problem complexes [20], [21]. MA usually consists of three steps. First, 
the problem complexity is categorized into several dimensions. Second, all possible conditions (also referred to as parameters) to each dimension are identified. These parameters represent the characteristics of each dimension. Finally, a morphological matrix is developed based on the identified dimensions and their assigned condition parameters [22]. Figure 3 depicts a morphological matrix, which contains a collection of identified features that are critical to selecting an assistance system. Key features for an adequate assistance system can be categorized into three groups: i) requirements regarding the application (software): How and to what extent maintenance information is presented to maintenance operators and engineers towards increasing their performance in an affordable manner? ii) requirements regarding the information system: How and to what extent maintenance information is tailored to the application? iii) requirements regarding the hardware: which hardware should be applied for the selected case?

\begin{tabular}{|c|c|c|c|c|c|c|}
\hline \multicolumn{7}{|c|}{ Requirement Morphology } \\
\hline Dimensions & \multicolumn{6}{|c|}{ Parameters } \\
\hline Type of support & \multicolumn{3}{|c|}{ Physically } & \multicolumn{3}{|c|}{ Information } \\
\hline Type of assistance systems & Stationary & \multicolumn{2}{|c|}{$\begin{array}{c}\text { Mobile install ation } \\
\text { (for example on a } \\
\text { notebook) }\end{array}$} & \multicolumn{2}{|c|}{$\begin{array}{l}\text { Hand device (for } \\
\text { example tablet or } \\
\text { smart phone) }\end{array}$} & $\begin{array}{c}\begin{array}{c}\text { Wearable (smart } \\
\text { glasses, smartwatch or } \\
\text { other) }\end{array} \\
\end{array}$ \\
\hline $\begin{array}{l}\text { Two hands are needed to carry out } \\
\text { the activity }\end{array}$ & \multicolumn{3}{|c|}{ No } & \multicolumn{3}{|c|}{ Yes } \\
\hline Application & Maintenance & \multicolumn{2}{|r|}{ Assembly } & \multicolumn{2}{|l|}{ Logistics } & Others \\
\hline Environmental conditions & wet & & dusty & $\begin{array}{r}\text { fluctuating lig } \\
\text { condition }\end{array}$ & $\begin{array}{l}\text { ghting } \\
\text { ns }\end{array}$ & noisy environment \\
\hline Operator & \multicolumn{2}{|l|}{ Gloves required } & \multicolumn{2}{|c|}{ Glasses required } & \multicolumn{2}{|c|}{ Helmet required } \\
\hline Type of use & \multicolumn{2}{|c|}{$\begin{array}{l}\text { One-time use (training. } \\
\text { education) }\end{array}$} & \multicolumn{2}{|c|}{ Selective use } & \multicolumn{2}{|r|}{ Regul ar use } \\
\hline Data transfer & \multicolumn{2}{|c|}{ Local via cable } & \multicolumn{2}{|c|}{ Wireless via private network } & \multicolumn{2}{|c|}{ Wreless via public network } \\
\hline Human Machine Interaction & \multicolumn{3}{|c|}{ Unimodal } & \multicolumn{3}{|c|}{ Multimodal } \\
\hline Type of interaction & \multicolumn{2}{|c|}{$\begin{array}{c}\text { Monol ogical (without } \\
\text { possibility of interaction) }\end{array}$} & \multicolumn{2}{|c|}{ Dialogical } & \multicolumn{2}{|c|}{$\begin{array}{l}\text { Communicating (for example } \\
\text { via chat functionality) }\end{array}$} \\
\hline support provided & Information & \multicolumn{2}{|c|}{ Instruction } & \multicolumn{2}{|c|}{ Interference } & \begin{tabular}{|c|}
$\begin{array}{c}\text { Engagement } \\
\text { Documentation }\end{array}$ \\
\end{tabular} \\
\hline Method of providing information & \multicolumn{2}{|l|}{ Visually } & \multicolumn{2}{|c|}{ Auditive } & \multicolumn{2}{|r|}{ Kinesthetic } \\
\hline $\begin{array}{l}\text { Type of Visual Information } \\
\text { Presentation }\end{array}$ & \multicolumn{2}{|l|}{ On-Screen Display } & \multicolumn{2}{|c|}{ On-Site Projection } & \multicolumn{2}{|r|}{$\begin{array}{l}\text { Augmented Reality } \\
\text { Visualtzation }\end{array}$} \\
\hline Scope of visual presentation & No vi sual information & \multicolumn{2}{|c|}{$\begin{array}{c}\text { Simple presentation } \\
\text { (texts, images or } \\
\text { markings) }\end{array}$} & \multicolumn{2}{|c|}{\begin{tabular}{c|} 
Mul timedia \\
presentation (videos, \\
animations, etc.)
\end{tabular}} & $\begin{array}{c}\text { Advanced } \\
\text { presentation (selected } \\
\text { drawing formats, etc.) }\end{array}$ \\
\hline Type of information input & Manual (via actuator) & \multicolumn{2}{|c|}{\begin{tabular}{c|}
$\begin{array}{l}\text { Verbal (via voice } \\
\text { control) }\end{array}$ \\
\end{tabular}} & Gesture recogr & gnition & $\begin{array}{c}\text { Automatic (via } \\
\text { sensors) }\end{array}$ \\
\hline Scope of user customization & $\begin{array}{l}\text { Predefined configuratio } \\
\text { regard to input and o }\end{array}$ & $\begin{array}{l}\text { on with } \\
\text { utput }\end{array}$ & $\begin{array}{l}\text { Individual ce } \\
\text { regarding ou }\end{array}$ & $\begin{array}{l}\text { onfiguration } \\
\text { tput possible }\end{array}$ & \begin{tabular}{|c} 
Indivic \\
regar
\end{tabular} & $\begin{array}{l}\text { dual configuration with } \\
\text { d to input and output } \\
\text { possible }\end{array}$ \\
\hline User categ ories & No user groups poss & & Different user $\mathrm{g}$ & groups possible & $\begin{array}{c}\text { Indivic } \\
\text { regar }\end{array}$ & $\begin{array}{l}\text { dual configuration with } \\
\text { d to input and output } \\
\text { possible }\end{array}$ \\
\hline User recognition & None & & User login and & dinitialization & $\begin{array}{l}\text { Autc } \\
\text { init }\end{array}$ & $\begin{array}{l}\text { Omatic detection and } \\
\text { ialization of the user }\end{array}$ \\
\hline Situation and motion detection & None & Using $\mathrm{m}$ & motion sensors & Using optical st & sensors & Other technology \\
\hline $\begin{array}{l}\text { Flexibility (with regard to } \\
\text { reconfiguration) }\end{array}$ & \begin{tabular}{|c|} 
Substantial \\
adjustments necessary
\end{tabular} & $\begin{array}{r}\text { Adjustm } \\
\text { (to be ce } \\
\text { spe }\end{array}$ & $\begin{array}{l}\text { ments necessary } \\
\text { carried out by } \\
\text { ipecialists) }\end{array}$ & $\begin{array}{r}\text { Adjustments ne } \\
\text { (by specialist or }\end{array}$ & $\begin{array}{l}\text { ecessary } \\
\text { on site) }\end{array}$ & $\begin{array}{c}\text { Small adaptation } \\
\text { necessary (by the user } \\
\text { on site) }\end{array}$ \\
\hline
\end{tabular}

Fig. 3 Morphological Matrix with defined dimensions and parameters

Based on a literature review and collection of manufacturers' data, we derived and determined 20 relevant criteria to assess the digital assistance system requirements. These requirements represent the dimensions within the morphological matrix. To further systematize the requirement analysis, the requirement elements are classified below using a morphological matrix in Fig. 3. This morphological matrix contains a collection of general condition parameters of the presented requirements. Based on the individual user-specific system requirements and the application scenario, the characteristic parameters can be identified. Thereby, the requirements are highlighted in color and optional requirements are shaded in color. It should be noticed that each answer can affect more than one choice regarding the hardware, software and visualization method. For the selection of a suitable digital assistance system a decision hierarchy 
needs to be constructed [22]. The underlying algorithm is based on Analytic Hierarchy Process (AHP) and fuzzy TOPSIS method principles [22]. An AHP method was applied to calculate the criteria priority weights, while fuzzy TOPSIS is used to evaluate and select a proper (combination of) digital assistance system(s).

\subsection{Device Selection Layer}

The Device selection layer represents the technology database and includes hardware and authoring software solutions. Due to the novelty of the topic, we had access to only a few practitioners with real-life implementations of DAS, especially smart glasses in this matter. For this reason, we have decided to elicit the functionalities from systematic literature review and market analysis. Based on ISO16290 the Technology Readiness Level of the emerging technologies on the market has been rated (see Fig. $1)$.

\section{Case Study: An Explanatory Process Model for DAM}

To reveal the functionality of the developed process model a maintenance scenario has been developed within the TU Wien Pilot-Factory Industry 4.0. Up to now, maintenance processes on the Universal Robot (UR5 laboratory robot) have only been carried out by experts. A proper DAS should guide workers step by step through the maintenance activities on the machine. Based on the developed selection model (cf. Section 2 ), the use of smart glasses is recommended. The chosen underlying software tool is called $\mathrm{MO}^{2} \mathrm{GO}$, a Process Modeling Tool developed by the Fraunhofer Institute for Production Systems and Design Technology IPK.

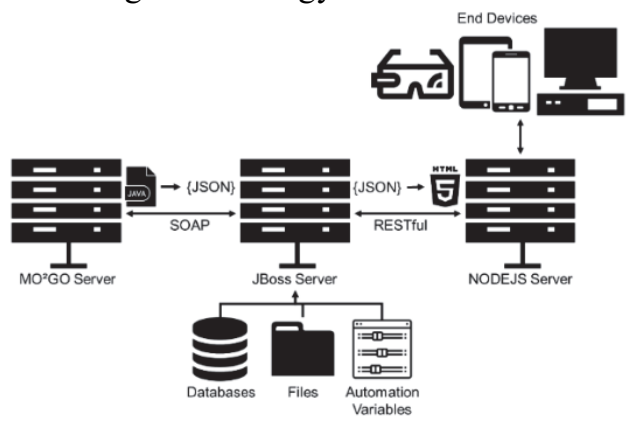

Fig. 5. Schematic software architecture for a context sensitive digital assistance system.

To model business processes, the method of integrated enterprise modeling (IEM) was developed in the 1990s at the Fraunhofer IPK [23]. The application of the IEM supports the description of business processes and their interactions with description elements of companies, such as organization, system, product or control. It is compatible with DIN EN ISO 19440 "Enterprise Integration - Constructs for Enterprise Modelling" and describes four element classes that can be related by five connection types. Table 1 shows a selection of element classes and connection types which are needed to model maintenance processes. The graphical modeling tool $\mathrm{MO}^{2} \mathrm{GO}[24]$, also developed at Fraunhofer IPK, is well suited to model the maintenance processes and forms the basis for the implementation of DAS[25]. $\mathrm{MO}^{2} \mathrm{GO}$ supports the XML (eXtensible 
Markup Language) exchange format, which is suitable for exchanging data between different applications. For the process step representation in a graphical user interface (GUI) of a digital assistance system, $\mathrm{MO}^{2} \mathrm{GO}$ offers an interface to provide the XML format of the process model as a JAVA object representation. The elements and their connections are then converted to JSON format and interpreted by an application interface (API) to link resources, generate context sensitive instructions and to initialize support functions on the maintained system during the various process steps. This JSON representation is then transformed to the web-capable HTML5 format in which JAVA Script is embedded to realize human-machine-interaction.

Table 1. Excerpt of IEM classes and connection types used for maintenance process modeling.

All objects that are changed by activities during a field service deploy-
ment, e. g. the product "machine tool with failure" (start condition) is
changed by the activity "performing service deployment" towards the
product "machine tool without failure" (final condition)
Changes the condition of a product

Figure 6 shows a scenario for the exchange of gripper jaws.

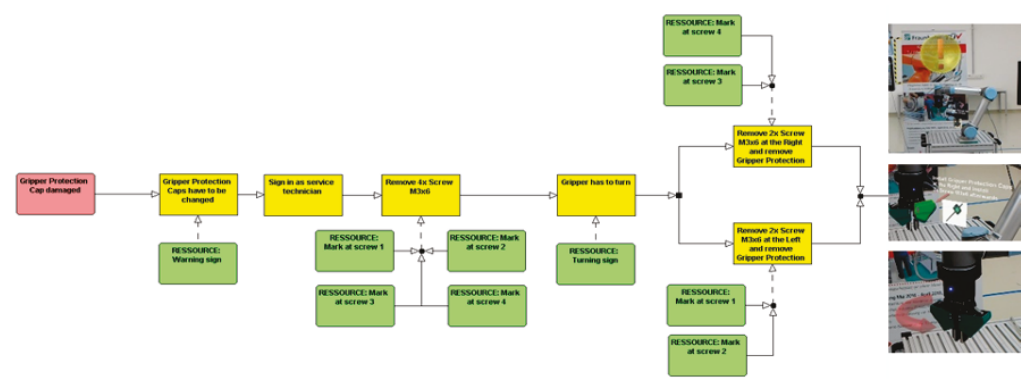

Fig. 6 Pictorial representation of a need for action and textual explanation of the activity combined with a pictorial representation of the tool and the object to be exchanged.

The maintenance operator is assisted by step-by-step instructions through virtual information directly on the work object. The user interface has been kept simple i.e. users 
see a complete virtual model of the equipment and the needed information to fullfil the maintenance task to the right. The $\mathrm{MO}^{2} \mathrm{GO}$ model is used to provide logic and information for the augmented reality (AR) based assistance system and to guide the worker through eight process steps.

\section{Conclusion and Outlook}

The presented approach can serve as guidance for the strategic evaluation of digital assistance solutions supporting maintenance processes. Combined with the proposed process-modeling tool the assistance system can provide the needed information to improve the maintenance efficiency. Since the proposed approach is currently a prototype, it encompasses some limitations that necessitate further research. First, the underlying decision hierarchy is based on experimental knowledge of experts and has been only validated through the proposed use case. In order to improve the quality of recommendations we need to collect feedback through employing the proposed approach to further practical use-cases. Second, the key information regarding hard- and software of the DAS on the market is extracted manually. By using various web crawling and web analytic techniques, including automated text- and web-mining methods, information can be extracted from documents such as product manuals and patent documents dynamically to identify the key features of existing products and technologies.

\section{Acknowledgement}

The authors would like to acknowledge the financial support of the European Commission provided through the H2020 project EPIC under the grant No. 739592. The TU Wien Pilot Factory Industry 4.0 has been partly funded by the public through the Austrian Research Promotion Agency (FFG) and several private industrial firms - our partners in the project.

\section{References}

1. Ansari, F.: Meta-Analysis of Knowledge Assets for Continuous Improvement of Maintenance Cost Controlling. Faculty of Science and Technology, University of Siegen (2014).

2. Nemeth, T., Ansari, F., Sihn, W., Haslhofer, B., Schindler, A.: PriMa-X: A Reference Model for Realizing Prescriptive Maintenance and Assessing its Maturity Enhanced by Machine Learning. Procedia CIRP, Vol. 72, pp. 1039-1044. (2018).

3. Glawar, R., Karner, M., Nemeth, T., Matyas, K., Sihn, W.: An Approach for the Integration of Anticipative Maintenance Strategies within a Production Planning and Control Model. Procedia CIRP $6746-51$, (2018).

4. Hao, Y., \& Helo, P.: The role of wearable devices in meeting the needs of cloud manufacturing: A case study. Robotics and Computer-Integrated Manufacturing, 45. Jg., S. 168-179. (2017).

5. Kernchen, A., Jachmann, D., Adler, S..: Assistenzsysteme für die Instandhaltung und Störungsbehebung. 21. Magdeburger Logistik Tage. Logistik neu denken und gestalten. S.195. (2016).

6. Niemöller, C., Metzger, D., Fellmann, M., Özcan, D., Thomas, O.: Shaping the future of mobile service support systems-ex-ante evaluation of smart glasses in technical customer service processes. Informatik 2016, (2016).

7. Erkoyuncu, J. A., del Amo, I. F., Dalle Mura, M., Roy, R., Dini, G.: Improving efficiency of industrial maintenance with context aware adaptive authoring in augmented reality. CIRP Annals 66.1. 465-468. (2017). 
8. Uhlmann E., Raue N., Geisert C.: Unterstützungspotenziale der Automatisierungstechnik im technischen Kundendienst. Summary of an explorative survey on best pactices in field service. Berlin: Fraunhofer IPK, (2013).

9. Mourtzis, D., Zogopoulos, V., Vlachou, E.: Augmented reality application to support remote maintenance as a service in the Robotics industry. Procedia CIRP 63: 46-51. (2017).

10. Neges, M., Wolf, M., Abramovici, M.: Secure access augmented reality solution for mobile maintenance support utilizing condition-oriented work instructions. Procedia CIRP, 38, 58-62. (2015).

11. Palmarini, R., Erkoyuncu, J., Rajkumar, R..: An innovative process to select Augmented Reality (AR) technology for maintenance. Procedia CIRP 59: 23-28 (2017).

12. Palmarini, R., Erkoyuncu, J. A., Roy, R., Torabmostaedi, H.: A systematic review of augmented reality applications in maintenance. Robotics and Computer-Integrated Manufacturing 49: 215228. (2018).

13. Hold, P., Erol, S., Reisinger, G., \& Sihn, W.: Planning and Evaluation of Digital Assistance Systems. Procedia Manufacturing 9:143-150. (2017).

14. Reisinger, G., Komenda, T., Hold, P., \& Sihn, W.: A Concept towards Automated Data-Driven Reconfiguration of Digital Assistance Systems. Education \& Training 2351: 9789. (2018).

15. Hohwieler E, Geisert C.: Intelligent Machines Offer Condition Monitoring and Maintenance Prediction Services. In: Teti R, editor. Proceedings of the 4th CIRP International Seminar on Intelligent Computation in Manufacturing Engineering (CIRP ICME '04). 30 June - 2 July 2004, Sorrento, Italy; pp. 599-604. (2004).

16. Hohwieler E, Berger R, Geisert C.: Condition Monitoring Services for e-Maintenance. In: Zaremba M, Sasiadek J, Erbe HH, editors. A proceedings volume from the 7th IFAC Symposium, Gatineau, Québec, Canada, 6-9 June 2004. Oxford: Elsevier pp. 239-244. (2005).

17. Ziegler, J., Heinze, S., Urbas, L.: The potential of smartwatches to support mobile industrial maintenance tasks. Emerging Technologies \& Factory Automation (ETFA), IEEE 20th Conference on. IEEE, (2015).

18. Bokrantz, J., Skoogh, A., Berlin, C., \& Stahre, J.: Maintenance in digitalised manufacturing: Delphi-based scenarios for 2030. International Journal of Production Economics, 191, 154-169. (2017).

19. Hold, P., Ranz, F., Hummel, V., Sihn, W..: Durchblick im Variantendschungel: visuelle Assistenzsysteme als Flexibilitätshebel auf dem Shop Floor (2015).

20. Ritchey, T.: Modeling alternative futures with general morphological analysis. World Future Review, 3(1), 83-94. (2011).

21. Ritchey, T.: Problem structuring using computer-aided morphological analysis. Journal of the Operational Research Society, 57(7), 792-801. (2006).

22. Im, K., Cho, H.: A systematic approach for developing a new business model using morphological analysis and integrated fuzzy approach. Expert Systems with Applications, 40(11), 4463-4477. (2013).

23. Spur, G.; Mertins, K.; Jochem, R.: Integrated Enterprise Modelling. Berlin, Wien, Zürich: Beuth. (1996).

24. Mertins K, Jaekel FW.: MO²GO: User Oriented Enterprise Models for Organisational and IT Solutions. In: Schmidt G, Mertins K, Bernus P, editors. Handbook on architectures of information systems. Berlin, New York: Springer p. 649-663. (2006).

25. Uhlmann, E.; Geisert, C.; Raue, N.; Gabriel, C.: Situation Adapted Field Service Support Using Business Process Models and ICT Based Human-Machine-Interaction. Procedia CIRP 47, p. 240 245. (2016). 
Open Access This chapter is licensed under the terms of the Creative Commons Attribution 4.0 International License (http://creativecommons.org/licenses/by/4.0/), which permits use, sharing, adaptation, distribution and reproduction in any medium or format, as long as you give appropriate credit to the original author(s) and the source, provide a link to the Creative Commons licence and indicate if changes were made

The images or other third party material in this chapter are included in the chapter's Creative Commons licence, unless indicated otherwise in a credit line to the material. If material is not included in the chapter's Creative Commons licence and your intended use is not permitted by statutory regulation or exceeds the permitted use, you will need to obtain permission directly from the copyright holder.

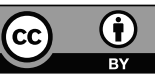

